\title{
Study of the Antimicrobial Effect of the Different Combinations of Silver Nano-Particles, Antibiotics, Laser and Photo-Sensitizer on Gram Positive and Gram Negative Bacteria
}

\section{Dalia El-Sayed Metwally ${ }^{1 *}$, Eglal Abd El-Salam El-Sherbiny ${ }^{1}$, Heba Saed Ramadan², Moustafa Moustafa Mohamed Ahmed ${ }^{2}$ and Mo'men Gameel Abd Elmageed ${ }^{3}$}

${ }^{1}$ Department of Microbiology, Medical Research Institute, University of Alexandria, Egypt

${ }^{2}$ Department of Medical Biophysics, Medical Research Institute,

University of Alexandria, Egypt

${ }^{3}$ Faculty of Science, Sohag University, Egypt

*Corresponding author

\section{A B S T R A C T}

Antimicrobial resistance is one of the major threats to human health. Thereby, discovering

Keywords

Staphylococcus aureus,

Enterobacter spp. isolates

Article Info

Accepted:

23 March 2018

Available Online:

10 April 2018 alternative strategies that can circumvent the mechanisms of resistance presents a big challenge. One of which is the use of nanotechnology and Photodynamic therapy. The current study included a total of 40 isolates that were; Twenty isolates of Staphylococcus aureus (14 MRSA and 6 MSSA isolates) and twenty isolates of multiple drug resistance (MDR) Gram negative bacteria (4 Escherichia coli, 4 Pseudomonas spp., 6 Klebsiella spp, 4 Proteus spp., 1 Acinetobacter spp. and one Enterobacter spp. isolates.). The effects due the interaction of silver nanoparticles (SNPs), laser in the presence of antibiotics (Polymyxin B for Gram negative bacteria and Fusidic acid for Gram positive bacteria) and photo-sensitizer; methylene blue (MB) on the test isolates was investigated by micro dilution test. The combinations that showed a statistically significant change in MIC values were those with the different combinations containing SNP. The effect of these combinations on the inhibition of growth of the Gram positive and/ or Gram negative isolates showed a statistically significant difference. In vivo studies are needed to determine whether considerable bacterial kills can be obtained in a wound model.

\section{Introduction}

Increasing hospital and community-acquired infections due to bacterial multidrug-resistant (MDR) infections against which current antibiotics are in-effective represent a serious public health problem. Antimicrobial resistance is, thus, one of the major threats to human health (Walker et al., 2009).
Antibiotic resistance genes have recently emerged (D'Costa et al., 2011), encouraged by inappropriate use of antibiotics (Dos Santos et al., 2014); hence, fighting antibiotic resistance anticipates innovation and the reduction of antibiotic misuse (Seppala et al., 1997). Thereby, discovering alternative strategies that can circumvent the mechanisms of resistance presents a big challenge- one of 
which is the use of nanotechnology and Photodynamic therapy (Jain et al., 2009; Bell et al., 2001).

The interaction of nanoparticles with biomolecules and microorganisms is an expanding field of research (Bell et al., 2001). In the field of infections, nanoparticles are being utilized as therapeutic tools against microbes (Amin et al., 2009). Various types of nanoparticles are available to treat wound infections (Mishra et al., 2008). Silver nanoparticles (SNPs) seem to be an alternative to antibiotics and have the ability to overcome the bacterial resistance against antibiotics (Sondi and Salopek-Sondi, 2014).

The mechanism of action of SNPs is not fully understood. The potent broad-spectrum activity against the different gram positive and gram negative bacteria seems to be due to multifaceted mechanisms (Lok et al., 2006).

The synergistic action of antimicrobial agents can reduce the need for high dosages and decrease side effects (Li et al., 2005).

Therefore the purpose of the current study was to identify the effects of the combination of SNPs and laser diode array (a maximum wavelength of $650 \mathrm{~nm}$ and a fluency rate of $3.90 \mathrm{~mW} / \mathrm{mm} 3$ ) in the presence of antibiotics and /or photo-sensitizer on Gram positive and Gram negative bacteria.

\section{Materials and Methods}

\section{Clinical specimens}

The current study included a total of 40 isolates; Twenty isolates of Staphylococcus aureus (14 MRSA and 6 MSSA isolates) and twenty multiple drug resistance (MDR) Gram negative bacterial isolates (4 Escherichia coli, 4 Pseudomonas spp., 6 Klebsiella spp, 4 Proteus spp., 1 Acinetobacter spp. and 1
Enterobacter spp isolates.).The bacterial isolates were collected from wound swabs from patients who attended the Microbiology Department of the Medical Research Institute, Alexandria University.

\section{Ethical considerations}

Under the guidelines of the committee of ethics of the medical research institute (MRI) of Alexandria University, an informed consent was obtained from patients prior to sample collection.

\section{Culture and identification}

The samples were cultured on blood agar and MacConkey agar. The isolated Gram positive and Gram negative bacteria were identified according to standard biochemical tests (Todar text book 2005). The isolates were preserved in $\mathrm{LB}$ broth at $-20^{\circ} \mathrm{C}$.

\section{Isolates were tested for their antibiotic} susceptibility

Using Bauer and Kirby method (Baur et al., 1966), the sensitivity test was carried out for the following antibiotics: $\beta$-lactams (ceftazidine, cefepime, piperacillintazobactam, imipenem and carbenicillin), aminoglycosides (gentamycin), macrolides (erythromycin) and fluroquinolones (levofloxacin, ciprofloxacin, norfloxacin and ofloxacin).

\section{Preparation of silver nanoparticles}

Silver nanoparticles were prepared by the chemical reduction method, based on the Turkevich mrethod (Turkevich et al., 1951) by reduction of silver nitrate $\left(\mathrm{AgNO}_{3}\right)$ with sodium citrate.

The growth of nanoparticles was monitored by $\mathrm{UV}$-vis spectrophotometer and complemented 
with characterization using transmission electron microscopy (TEM).

\section{Particle size distribution}

The particle size distribution of the silver nanoparticles was determined by laser light scattering on a Beckman Coulter Particle Size Analyzer (N5 submicron particle size analyzer, Japan).

\section{Determination of Minimum Inhibitory Concentration (MIC)}

Each isolate was freshly thawed and subcultured on blood agar prior to testing. The pure colonies were suspended in nutrient broth and adjusted to $0.5 \mathrm{McFarland}$ standards. Broth microdilution tests were performed according to the CLSI recommendations (CLSI, 2015) to determine the isolate MIC for polymyxin B (with Gram negative bacteria) and fusidic acid (with Gram positive bacteria) in the presence and absence of Silver nanoparticles at a fixed concentration of 100 $\mu \mathrm{g} / \mathrm{ml}$

\section{Determination of photo-sensitizer effect}

The effect of a fixed concentration of $100 \mu \mathrm{g} / \mathrm{ml}$ of methylene blue was studied on the 40 Gram positive and Gram negative isolates included in the study. Negative control wells contained broth alone and positive control wells contained broth plus the isolate in question. Results were read visually after an overnight incubation at $35^{\circ} \mathrm{C}$.

Determination the effect of laser irradiation alone and with SNPs, photo-sensitizer and antibiotics

\section{Visible diode laser}

In the present work a homemade Diode laser multipurpose array derived with IC PIC microcontroller was designed and constructed (Figure 1). The laser diode array was constructed over micro titer plate [96 wells ( 8 $x$ 12)]. These arrays were suitably coupled to irradiate bacterial suspensions inside the corresponding micro titer plates. Each diode laser was derived with a maximum power of $150 \mathrm{~mW}$ and emits a red color light at maximum wavelength of $650 \mathrm{~nm}$. During the experiments, the laser beam was delivered to the wells of the micro-titer plate containing samples with an irradiation spot of a 7-mm diameter. The fluency rate was $3.90 \mathrm{~mW} / \mathrm{mm}^{3}$. The derive circuit operated at a low voltage of 5 volt with a maximum consumption power of 15 Watt. An air fan was used for cooling the laser diode arrays.

\section{Statistical analysis of the data}

Data was fed to the computer and analyzed using IBM SPSS software package version 20.0 .

\section{Results and Discussion}

Characterization of the prepared silver nanopartices (SNPs)

The results of particle size analyzer are shown in (Figure 2). Transmission electron microscope (TEM) examination indicated the presence of triangle shaped silver nanoparticles with low level of adhesion among particles and high level of uniformity (Figure 3). The plasmon absorption spectra of prepared silver nanoparticles were evaluated by UV-visible spectrophotometer and the results obtained revealed that the plasmon absorption of prepared nanoparticles was clearly visible and its maximum absorption peak was at $610 \mathrm{~nm}$ (Figure 4).

Several studies reported that silver has antimicrobial effect against more than 650 pathogens, showing a broad spectrum of 
activity. Its use in the form of nanoparticles exalts this property, allowing its application (Dastjerdi et al., 2010; Yoon et al., 2007). Thereby, SNPs is considered one of the most suitable strategies to solve the problem of bacterial multidrug resistance (Franci et al., 2015; Salomoni et al., 2015; Rai et al., 2012).

The antimicrobial effect of PDT is still in the experimental phase. A light-sensitive nontoxic compound (photo-sensitizer-PS) is applied on the site of infection and, after an incubation period (to allow accumulation of the PS in the bacterial cells), the area is irradiated with a visible light source of appropriate wavelength with maximum absorption by the PS (Gattuso Rai et al., 2016; Jori et al., 2006).

In the current series, the twenty (100\%) Staphylococcus isolates showed inhibition of growth in the presence of truncated triangular SNPs. Meanwhile, there was inhibition of growth in only six $(30 \%)$ out of the twenty Gram negative isolates (a single isolate of each of Escherichia coli, Pseudomonas spp., Klebsiella spp., Proteus spp., Acinetobacter spp., and Enterobacter spp.). There was a highly significant statistical difference between the number of Gram positive and Gram negative isolates that showed inhibition of growth in response to SNPs $(\mathrm{P}=0.0027)$.

Similar to our results, Shrivastava et al., conducted a study on Four bacterial strains $(E$. coli; ampicillin-resistant E. coli; multi-drug resistant $S$. typhi and $S$. aureus).

They observed that Gram negative bacteria were less susceptible to SNPs because of the positive charges of the silver nanoparticles interact with the Gram negative lipopolysaccharide with more affinity than with the Gram positive cell wall, which has fewer interaction sites with positive charges (Shrivastava et al., 2007).
In contrast to our results, Pal et al., reported that for truncated triangular particles, almost complete inhibition of Gram negative bacterial growth was observed even at a total silver concentration of $1 \mu \mathrm{g} / \mathrm{ml}$. They concluded that silver nanoparticles undergo a shape dependent interaction with the Gram-negative organisms (Pal et al., 2007). Kong and Jang, and Petica et al., have proven that silver nanoparticles exert similar effect on both Gram positive and Gram negative bacteria (Kong et al., 2008; Petica et al., 2008).

Previous studies indicate that SNPs' mode of action is different from that of antibiotics. Microbes are unlikely to develop resistance against silver, as they do against conventional and narrow-target antibiotics, because the metal attacks a broad range of targets in the bacteria, which implies that they would have to develop multiple mutations simultaneously (Pal et al., 2007).

The synergistic action of antimicrobial agents can reduce the need for high dosages and minimize side effects (Li et al., 2005). It has been reported that, the combination of SNPs and Polymyxin B showed the most pronounced antibiotic synergy against Gram negative bacteria. It turns out that polymyxin B makes pores in the outer bacterial membrane thereby, enhances the antibacterial effect of the silver nanoparticles (Ruden et al., 2009).

Fusidic acid has low toxicity and a unique mechanism of action (elongation factor $\mathrm{G}$ [EFG]) that lacks significant cross-resistance to other antibacterial classes. Thus, it is regarded as a potentially valuable therapeutic option. To diminish the chance of the development of fusidic acid resistance, it has been strongly recommended that fusidic acid should not be administered as a mono therapy but concomitantly with another antimicrobial agent (Howden et al., 2006) (Fig. 5-8; Table $1-6)$. 
Table.1 The comparison of the effect of different combinations on the growth of the 20 Gram negative isolates in the absence (Dark toxicity) or presence of laser for 10 minutes

\begin{tabular}{|c|c|c|c|c|c|}
\hline & \multicolumn{2}{|c|}{$\begin{array}{c}\text { Gram Negative } \\
20(100 \%)(\text { Dark toxicity) }\end{array}$} & \multicolumn{2}{|c|}{$\begin{array}{l}\text { Gram Negative } \\
20(100 \%) \text { with laser }\end{array}$} & \multirow[t]{2}{*}{ p-value } \\
\hline & Resistant & Sensitive & Resistant & Sensitive & \\
\hline Polymyxin B & $20(100 \%)$ & $0(00 \%)$ & $20(100 \%)$ & $0(00 \%)$ & 1.0 \\
\hline (SNPs) & $14(70 \%)$ & $6(30 \%)$ & $14(70 \%)$ & $6(30 \%)$ & 1.0 \\
\hline (MB) & $20(100 \%)$ & $0(0 \%)$ & $20(100 \%)$ & $0(0 \%)$ & 1.0 \\
\hline (SNPs) + Polymyxin B & $14(70 \%)$ & $6(30 \%)$ & $14(70 \%)$ & $6(30 \%)$ & 1.0 \\
\hline$(\mathbf{S N P s})+(\mathbf{M B})$ & $14(70 \%)$ & $6(30 \%)$ & $14(70 \%)$ & $6(30 \%)$ & 1.0 \\
\hline (SNPs) + Polymyxin B + (MB) & $13(65 \%)$ & $7(35 \%)$ & $14(70 \%)$ & $6(30 \%)$ & 0.7359 \\
\hline
\end{tabular}

Table.2 The comparison of the effect of different combinations on the growth of the 20 Gram positive isolates in the absence (Dark toxicity) or presence of laser for 10 minutes

\begin{tabular}{|l|l|} 
& \\
\hline fusidic acid \\
\hline (SNPs) \\
\hline (MB) \\
\hline (SNPS) + fusidic acid \\
\hline (SNPS) + (MB) \\
\hline
\end{tabular}

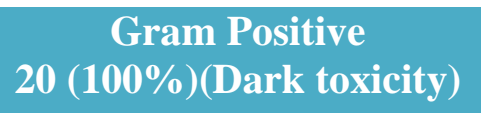

\begin{tabular}{|c|c|c|c|c|}
\hline Resistant & Sensitive & Resistant & Sensitive & \\
\hline $20(100 \%)$ & $0(00 \%)$ & $17(85 \%)$ & $3(15 \%)$ & 0.1736 \\
\hline $0(0 \%)$ & $20(100 \%)$ & $0(0 \%)$ & $20(100 \%)$ & 1.0 \\
\hline $15(75 \%)$ & $5(25 \%)$ & $15(75 \%)$ & $5(25 \%)$ & 1.0 \\
\hline $0(0 \%)$ & $20(100 \%)$ & $0(0 \%)$ & $20(100 \%)$ & 1.0 \\
\hline $0(0 \%)$ & $20(100 \%)$ & $0(0 \%)$ & $20(100 \%)$ & 1.0 \\
\hline $0(0 \%)$ & $20(100 \%)$ & $0(0 \%)$ & $20(100 \%)$ & 1.0 \\
\hline
\end{tabular}

Table.3 The comparison of the effect of different combinations on the growth of the 14 Gram positive (MRSA) isolates in the absence (Dark toxicity) or presence of laser for 10 minutes

\begin{tabular}{|c|c|c|c|c|c|}
\hline & \multicolumn{2}{|c|}{$\begin{array}{c}\text { (MRSA) } \\
14(100 \%)(\text { Dark toxicity) }\end{array}$} & \multicolumn{2}{|c|}{$\begin{array}{c}(\text { MRSA }) \\
14(100 \%) \text { with laser }\end{array}$} & \multirow[t]{2}{*}{ p-value } \\
\hline & Resistant & Sensitive & Resistant & Sensitive & \\
\hline Fusidic acid & $14(100 \%)$ & $0(0 \%)$ & $12(85.7 \%)$ & $2(14.3 \%)$ & 0.2709 \\
\hline (SNPs) & $0(0 \%)$ & $14(100 \%)$ & $0(0 \%)$ & $14(100 \%)$ & 1.0 \\
\hline$(\mathrm{MB})$ & $10(71.4 \%)$ & $4(28.6 \%)$ & $10(71.4 \%)$ & $4(28.6 \%)$ & 1.0 \\
\hline (SNPs) + fusidic acid & $0(0 \%)$ & $14(100 \%)$ & $0(0 \%)$ & $14(100 \%)$ & 1.0 \\
\hline$(\mathrm{SNPs})+(\mathrm{MB})$ & $0(0 \%)$ & $14(100 \%)$ & $0(0 \%)$ & $14(100 \%)$ & 1.0 \\
\hline $\begin{array}{l}\text { (SNPs) + fusidic acid } \\
+(\mathrm{MB})\end{array}$ & $0(0 \%)$ & $14(100 \%)$ & $0(0 \%)$ & $14(100 \%)$ & 1.0 \\
\hline
\end{tabular}


Table.4 The comparison of the effect of different combinations on the growth of the 6 Gram positive (MSSA) isolates in the absence (Dark toxicity) or presence of laser for 10 minutes

\begin{tabular}{|l|c|c|c|c|c|}
\hline & \multicolumn{2}{|c|}{$($ MSSA) } & \multicolumn{2}{c|}{ (MSSA) } & p-value \\
\cline { 1 - 5 } & 6esistant & Sensitive & Resistant & Sensitive & \\
\hline Fusidic acid & $6(100 \%)$ & $0(0 \%)$ & $5(83.3 \%)$ & $1(16.7 \%)$ & 0.4651 \\
\hline (SNPs) & $0(0 \%)$ & $6(100 \%)$ & $0(0 \%)$ & $6(100 \%)$ & 1.0 \\
\hline (MIB) & $5(83.3 \%)$ & $1(16.7 \%)$ & $5(83.3 \%)$ & $1(16.7 \%)$ & 1.0 \\
\hline (SNPs) + fusidic acid & $0(0 \%)$ & $6(100 \%)$ & $0(0 \%)$ & $6(100 \%)$ & 1.0 \\
\hline (SNPs) + (MB) & $0(0 \%)$ & $6(100 \%)$ & $0(0 \%)$ & $6(100 \%)$ & 1.0 \\
\hline (SNPs) + fusidic acid +(MB) & $0(0 \%)$ & $6(100 \%)$ & $0(0 \%)$ & $6(100 \%)$ & 1.0 \\
\hline
\end{tabular}

Table.5 The determination of MIC values of fusidic acid and Polymyxin B either alone or in different combinations on the growth of Gram positive and gram negative isolates in absence or presence of laser

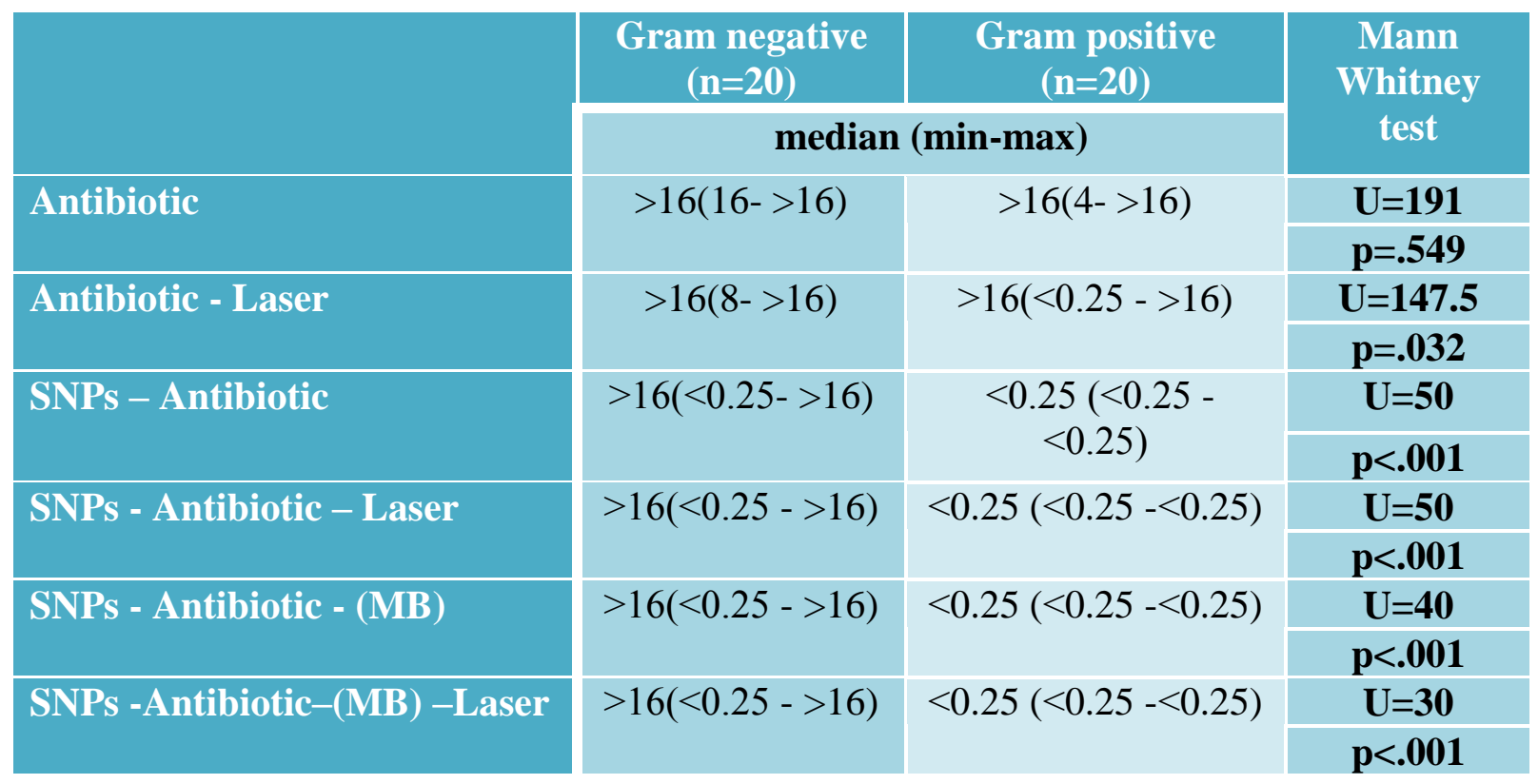

Broth microdilution tests were performed according to the CLSI recommendations $\mathrm{p} \leq 0 . .05$ are significant

U: MannWhitney test 
Table.6 The determination of MIC values of fusidic acid either alone or in different combinations on the growth of Gram positive isolates in absence or presence of laser for 10 minutes

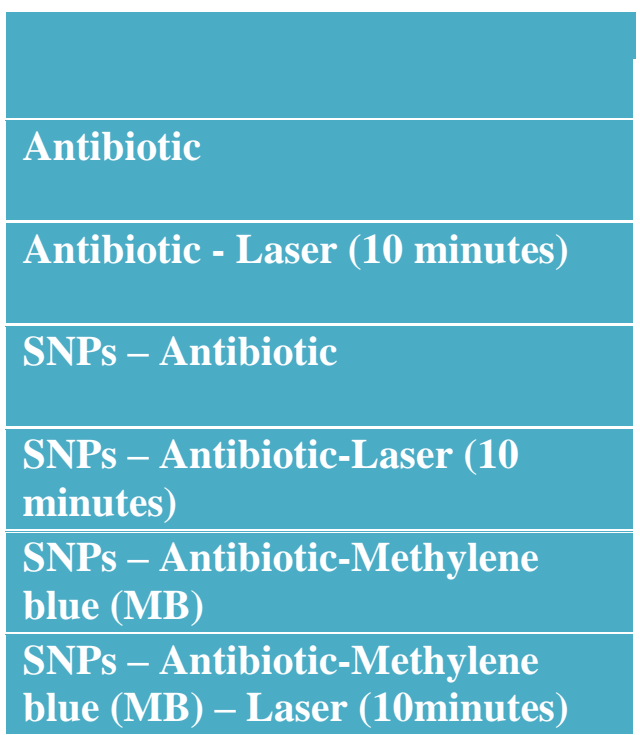

\begin{tabular}{|r|c|c|}
\hline \multicolumn{1}{|c|}{ MIRSA $(\mathbf{n = 1 4})$} & MSSA $(\mathbf{n = 6})$ & Mann Whitney \\
\hline \multicolumn{2}{|c|}{ median (min-max) } & test \\
\hline$>16(4->16)$ & $>16(>16->16)$ & $\mathbf{U = 4 9}$ \\
\hline$>16(<0.25->32)$ & $>16(<0.25->16)$ & $\mathbf{p = . 6 0 2}$ \\
\hline$<0.25(<0.25-<0.25)$ & $<0.25(<0.25-<0.25)$ & $\mathbf{U = 5 2 . 5}$ \\
\hline$<0.25(<0.25-<0.25)$ & $<0.25(<0.25-<0.25)$ & $\mathbf{U = 4 2}$ \\
\hline$<0.25(<0.25-<0.25)$ & $<0.25(<0.25-<0.25)$ & $\mathbf{~}=\mathbf{U}=\mathbf{4 2}$ \\
\hline$<0.25(<0.25-<0.25)$ & $<0.25(<0.25-<0.25)$ & $\mathbf{p = 1}$ \\
\hline & & $\mathbf{U = 4 2}$ \\
\hline
\end{tabular}

Table.7 The effect of fusidic acid and Polymyxin B either alone or in different combinations on the growth of Gram positive and Gram negative isolates

\begin{tabular}{|c|c|c|c|c|c|c|c|c|}
\hline & Antibiotic & $\begin{array}{c}\text { Ab.t } \\
\text { Laser } \\
10 \\
\text { mins }\end{array}$ & $\begin{array}{c}\text { SNPs + } \\
\text { Ab. }\end{array}$ & $\begin{array}{c}\text { SNPs + } \\
\text { Ab.+ } \\
\text { Laser } 10 \\
\text { mins }\end{array}$ & $\begin{array}{c}\text { SNPs + } \\
\text { Ab.t } \\
\text { (MB) }\end{array}$ & $\begin{array}{c}\text { SNPs + Ab. } \\
+(\mathrm{MB})+ \\
\text { Laser } \\
\text { 10min }\end{array}$ & \multirow[t]{2}{*}{$\begin{array}{l}\text { Statistical } \\
\text { significance }\end{array}$} \\
\hline & & \multicolumn{6}{|c|}{ median(min-max) } & \\
\hline 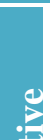 & Mean rank & $\begin{array}{c}>16(16- \\
>16) \\
4.15\end{array}$ & $\begin{array}{l}>16(8- \\
>16) \\
4.25\end{array}$ & $\begin{array}{c}>16(<0.25 \\
->16) \\
3.05\end{array}$ & $\begin{array}{c}>16(<0.25 \\
->16) \\
3.05\end{array}$ & $\begin{array}{c}>16(<0.25 \\
->16) \\
3.1\end{array}$ & $\begin{array}{c}>16(<0.25- \\
>16) \\
3.4\end{array}$ & $\mathrm{Fr}=26.66$ \\
\hline gี & & & & & & & & $\mathrm{p}<.001^{*}$ \\
\hline है & $\begin{array}{l}\text { Antibiotic } \\
\text { (p1) }\end{array}$ & & $\mathrm{p}>.05$ & $p>.05$ & & & & \\
\hline E & $\begin{array}{l}\text { Antibiotic } \\
+ \text { Laser } 10 \\
\text { mins (p2) }\end{array}$ & & & $\mathrm{p}=.011$ & & & & \\
\hline 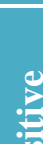 & & $\begin{array}{l}>16(4- \\
>16)\end{array}$ & $\begin{array}{c}>16(<0 . \\
25- \\
>16)\end{array}$ & $\begin{array}{l}<0.25 \\
(<0.25- \\
<0.25)\end{array}$ & $\begin{array}{l}<0.25 \\
(<0.25- \\
<0.25)\end{array}$ & $\begin{array}{l}<0.25 \\
(<0.25- \\
<0.25)\end{array}$ & $\begin{array}{l}<0.25 \\
(<0.25- \\
<0.25)\end{array}$ & $\mathrm{Fr}=91.64$ \\
\hline 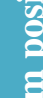 & $\begin{array}{l}\text { Antibiotic } \\
(\mathrm{p} 1)\end{array}$ & & & $\mathrm{p}<.001 * *$ & $\mathrm{p}<.001 * *$ & $\mathrm{p}<.001 * *$ & $\mathrm{p}<.001 * *$ & $\mathrm{p}<.001 *$ \\
\hline E & $\begin{array}{c}\text { Antibiotic } \\
+ \text { Laser } 10 \\
\text { mins (p2) }\end{array}$ & & & $\mathrm{p}<.001 * *$ & $\mathrm{p}<.001 * *$ & $\mathrm{p}<.001 * *$ & $\mathrm{p}<.001 * *$ & \\
\hline
\end{tabular}

$*$ Results $\leq .05$ are significant

**Adjusted $\mathrm{p}$

Fr: Friedman test

${ }^{\mathbb{T}}$ Results $\leq .016$ are significant by Wilcoxon signed rank test. 
Fig.1 96 laser diode array and driver

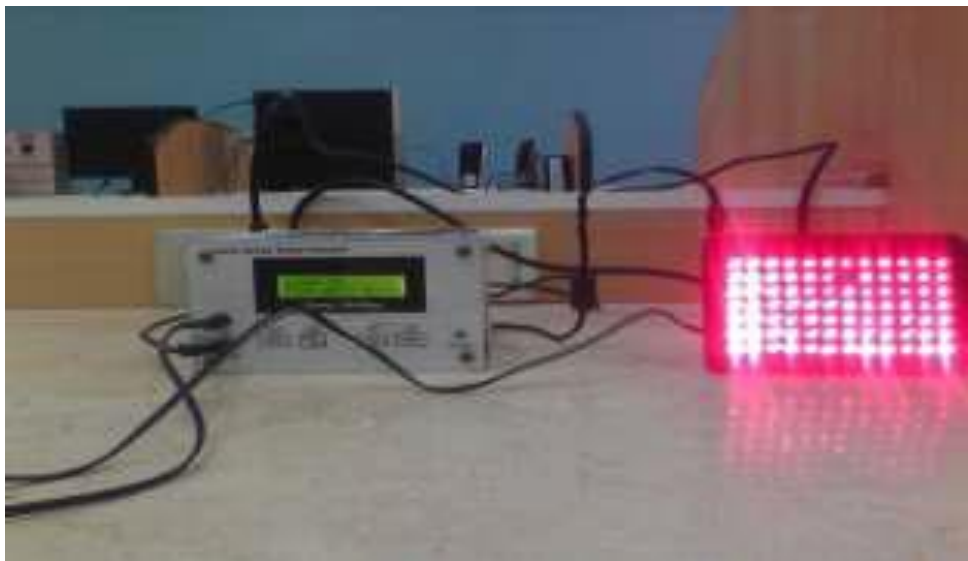

Fig.2 Particle size distribution of prepared silver nanoparticles showing mean particle size of 36 $\mathrm{nm}$ at diffraction angle of $11.1^{\circ}$

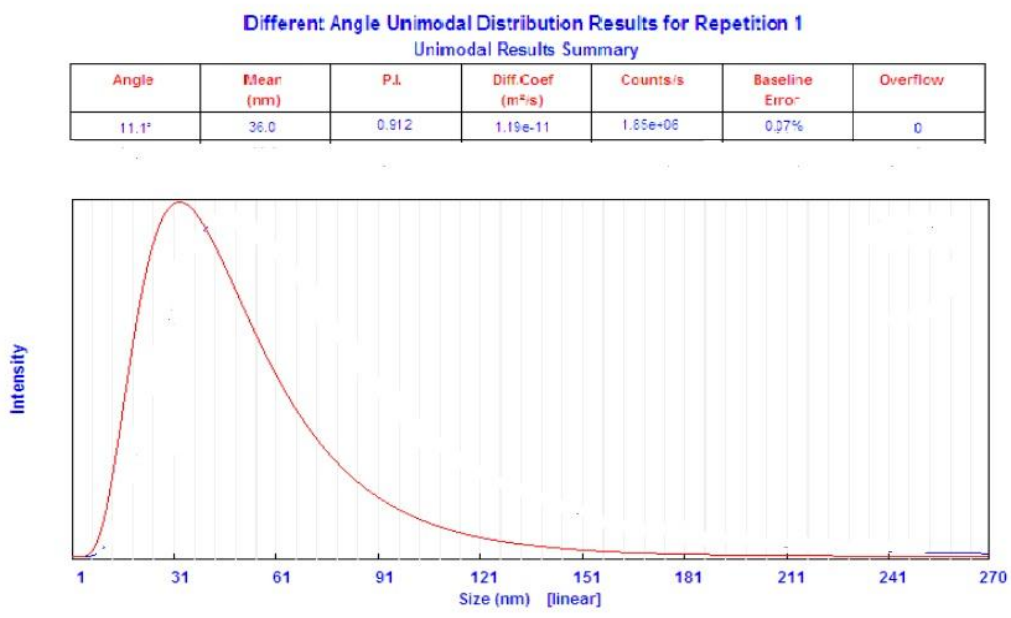

Fig.3 TEM of triangle-shaped silver nanoparticles (Mag. 35000x)

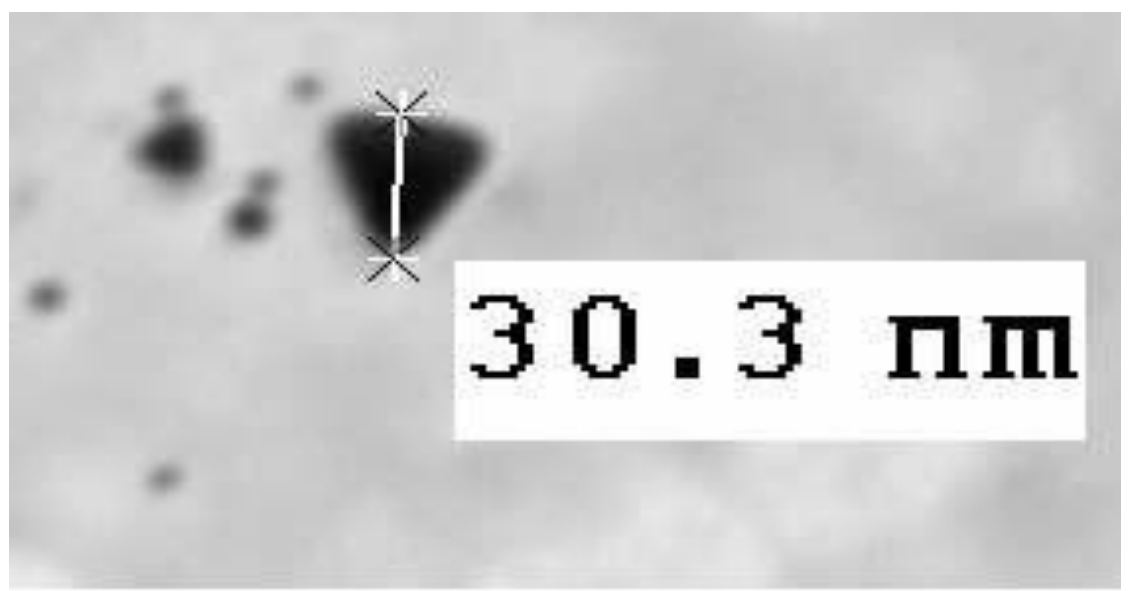


Fig.4 Absorption spectra of prepared coated silver nanoparticles $(\lambda \max =610 \mathrm{~nm})$

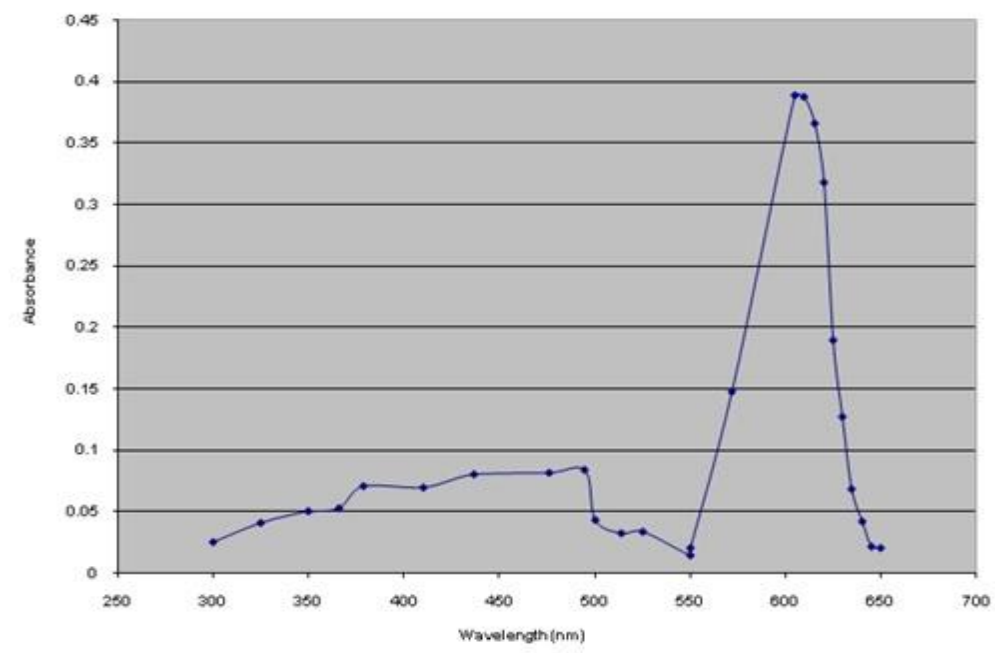

Fig.5 Effect of Methylene Blue (MB) in the absence and presence of laser on the growth of Gram negative bacteria

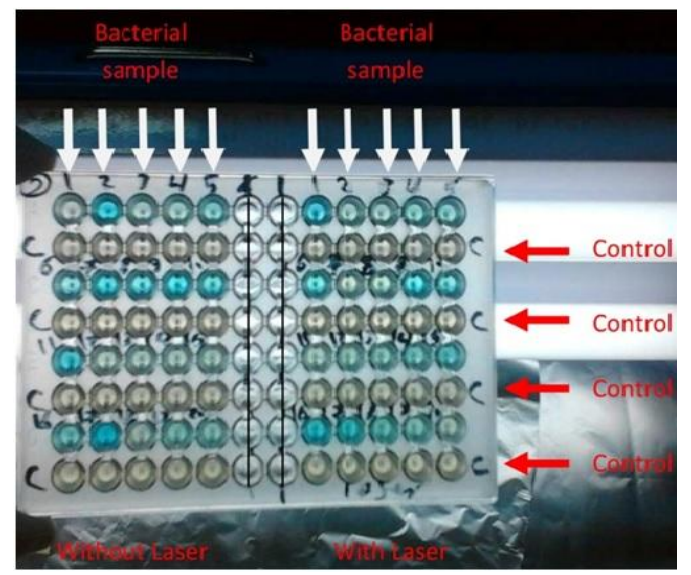

Fig.6 The combined effect of silver nanoparticles with fusidic acid on Gram positive bacteria

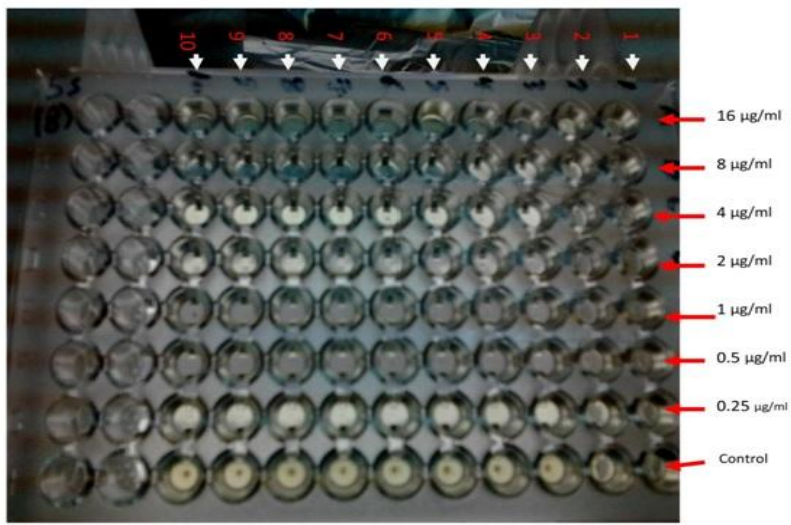


Fig.7 The effect of polymyxin B alone and in different combinations on the growth of the 20 Gram negative bacterial isolates according to the CLSI standard breakpoints

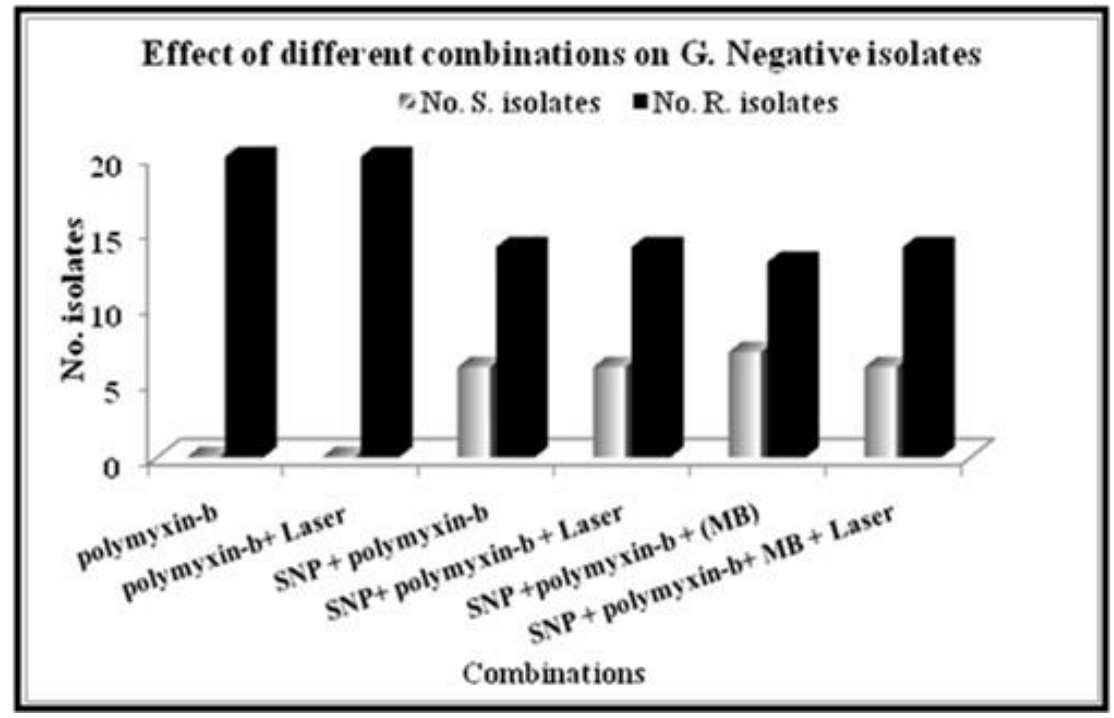

Fig.8 The effect of fusidic acid alone and in different combination on the growth of the 20 Gram positive bacterial isolates according to the CLSI standard breakpoints

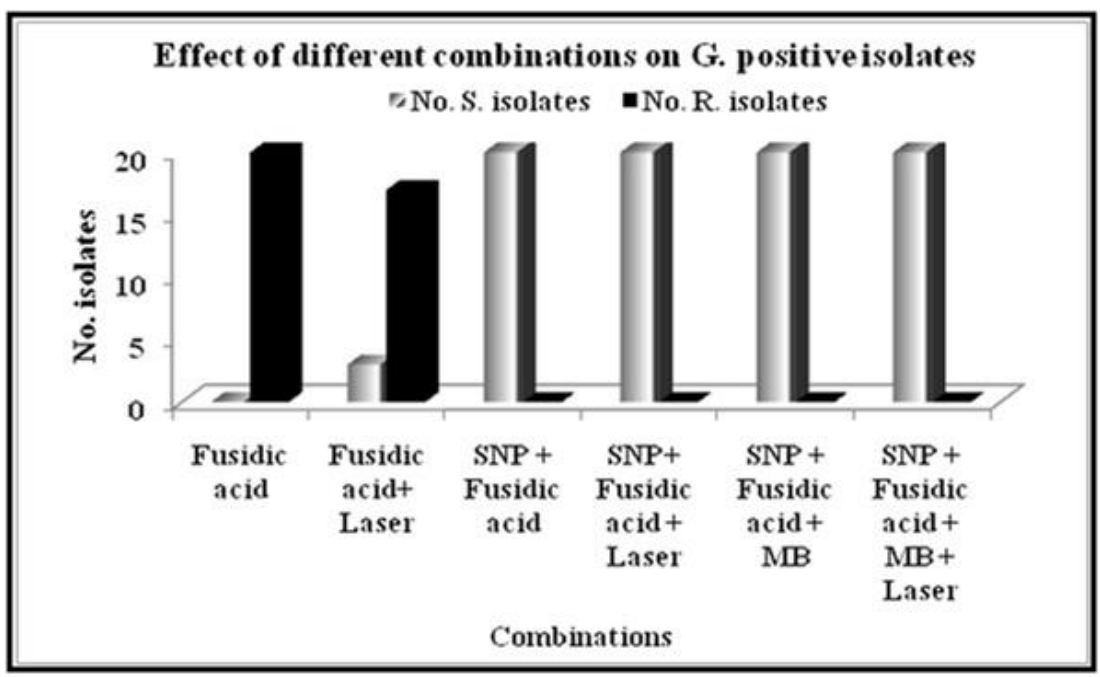

In the current study, none of the tested Gram negative or Gram positive isolates showed inhibition of growth in the presence of antibiotic alone.

On the other hand, six Gram negative isolates (a single isolate of each of Escherichia coli, Acinetobacter spp., Enterobacter spp., Proteus spp., Pseudomonas spp., and Klebsiella spp., the same isolates that showed inhibition of growth in the presence of SNPs alone) showed conversion from resistant to sensitive in the presence of polymxin B and SNPs.

Meanwhile, all of the 20 (100\%) Gram positive isolates (MRSA and MSSA isolates) showed conversion from resistant to sensitive in the presence of fusidic acid with SNPs. There was a statistically significant difference 
between the effect of antibiotic alone and antibiotic with SNPs on Gram positive isolates $(\mathrm{P}=0.0002)$. Meanwhile, the Gram negative isolates showed no such statistically significant effect $(\mathrm{P}=0.0534)$.

In contrast to our results, Fayaz et al., (2009) reported that; SNP showed an overall synergistic antibacterial effect with several antibiotics against Gram-positive and Gramnegative bacteria, including multiresistant strains (Fayaz et al., 2010; Birla et al., 2009). On the other hand, clindamycin was reported to show an additive effect with SNPs on MRSA, S. aureus 6538 P, S. flexneri and $B$. subtilis (Shahverdi et al., 2007).

Meanwhile, De Sousa et al., observed an antagonistic effect of SNPs tested in combination with a group of nineteen antibiotics against Gram-positive and Gramnegative strains such as multiple-drug resistant (MDR) E. coli, S. enteric and $S$. Typhi (De Sousa et al., 2006).

Several studies of photodynamic action of MB on pathogenic bacteria have been performed. MB easily crosses bacterial cell walls. It binds easily to the negative charge of the lipopolysaccharides of Gram-negative bacteria. Gram-positive bacteria have only capsular material and peptidoglycan outside of the cytoplasmic membrane; thereby, enabling MB to cross it (Zeina et al., 2001; Usacheva et al., 2001 Kashef et al., 2011).

In the current study, none of the Gram negative bacteria showed inhibition of growth in response to laser for $10 \mathrm{~min}$. Similar results were obtained either in response to $100 \mu \mathrm{g} / \mathrm{ml}$ methylene blue alone (dark toxicity) or in combination with laser. Similar results were reported by Kashef et al., (Kashef et al., 2011) Meanwhile, Usacheva et al., demonstrated that all of the irradiated Gram positive and Gram-negative organisms were eradicated to some extent by red laser light in the presence of Toluidine blue or $\mathrm{MB}$ (Usacheva et al., 2001).

There are conflicting results for both laboratory studies and clinical trials, even when using the same laser wavelength. Many reasons exist for this puzzle, such as different laser wavelengths; variability in laser parameters; insufficient reporting of parameters which, in turn, does not allow calculation of energy density; differences in experimental design, protocols and controls. Simply put, there is insufficient evidence to suggest that any specific wavelength of laser. Also, differences in bacterial cell structure and virulence may play a role (Cobb, 2006).

If antibiotics are used in combination with photodynamic therapy, biochemical changes in the organic molecules of the cell that arise from alteration in enzyme molecules or chemical break down of structural molecules, especially in the cell membrane may lead to increasing the sensitivity of the bacteria to the antibiotics.

The antimicrobial susceptibility of bacteria is regulated by several factors that may modify drug efficacy.

It was found that the two most important environmental factors that affect the susceptibility of the microorganism to the antibiotics are the $\mathrm{pH}$ and temperature (Segun, 2004; Anwer et al., 2007).

On the other hand, methylene blue showed a statistically significant difference between its inhibitory effect on the Gram negative and Gram positive isolates when used in combination with SNP and SNP with antibiotic ( $\mathrm{p}=0.0027,0.0042$; respectively).

Ahmadov, et al., reported that Ag@MS@HPIX hybrid photosensitizers 
displayed significant singlet oxygen generation with broadened excitation profile.

They demonstrated remarkably high PDI efficacy against $S$. aureus (ATCC BAA-44), a multidrug-resistant strain without involving antibiotics (Ahmadov et al., 2016).

In the present study, the combinations that showed a statistically significant change in MIC values were with the different combinations containing SNP;

SNPs + Antibiotic,

SNPs + Antibiotic + Laser (for 10 minutes)

SNPs + Antibiotic + Photosisitizer (MB),

SNPs + Antibiotic+ Photosisitizer (MB) + Laser (for 10 minutes).

These results can be attributed to the effect of SNPs, as the effect the different combinations containing SNPs were associated with a marked increase in the number of sensitive isolates among both the Gram positive and Gram negative isolates.

\section{Recommendations}

Evaluation of differences between the preformulated nanoparticles bound antibiotics versus the concomitant addition of the silver nanoparticles and antibiotics.

The comparison of silver nanoparticles produced chemically or biosynthetically, merit more profound investigation.

In vivo studies are needed to determine whether considerable bacterial kills can be obtained in a wound model.

The insufficient evidence to suggest specific wavelength to test the antibacterial effect of laser, lack of proper controls, differences in experimental design and protocols should be the target for standardization.

\section{References}

Ahmadov, T, O., Ding, R., Zhang, J., Wang, P., Tang, H., Zhang. 2016. Silver nanoparticle-enhanced hybrid photosensitizer for photoinactivation of multidrug resistant Staphylococcus aureus (MRSA). RSC Adv. 6: 5431854321.

Amin, R., Mohamed, M., Ramadan, M., Verwanger, T., Krammer, B.2009.Rapid and sensitive microplate assay for screening the effect of silver and gold nanoparticles on bacteria. Nanomedicine. 4: 637-643.

Anwer, A, G., Husien, A, S. 2007. Combination effect of laser, antibiotics and different temperature on locally isolated Pseudomonas aeruginosa. Iraqi $\mathrm{J}$ Laser B. 6: 21-30.

Baur, A., Kirby, W., Sherris, J., Turch, M. 1966. Antibiotic susceptibility testing by standardized single disc method. Am J Clin Pathol. 45: 493-496.

Bell, W.C., Myrick ML. 2001.Preparation and characterization of nanoscale silver colloids by two novel synthetic routes. J Colloid Interface Sci. 242: 300-305.

Birla SS, Tiwari VV, Gade AK, Ingle AP, Yadav AP, Rai MK. 2009. Fabrication of silver nanoparticles by Phoma glomerata and its combined effect against Escherichia coli, Pseudomonas aeruginosa and Staphylococcus aureus. Lett Appl Microbiol. 48(2): 173-179.

Clinical Laboratory Standards Institute (CLSI). Performance standards for antimicrobial susceptibility testing. Approved Standard; Twenty fifth informational supplement. January 2015.

Cobb, C, M. 2006. Lasers in periodontics: a review of the literature. J Periodontol. 77(4): 545-564. 
D’Costa, V.M., King, C.E., Kalan, L., Morar, M., Sung, W.W., Schwarz, C., Froese, D., Zazula, G., Calmels, F., Debruyne, R. 2011. Antibiotic resistance is ancient. Nature.477: 457-461.

Dastjerdi, R., Montazer, M. 2010.A review on the application of inorganic nanostructured materials in the modification of textiles: focus on antimicrobial properties. Colloids Surf B Biointerfaces. 79(1):518.

De Sousa, A., Mehta, D., Leavitt, R, W. 2006. Bactericidal activity of combinations of silver water dispersion TM with 19 antibiotics against seven microbial strains. Curr Sci. 91(7): 926-929.

Dos Santos, C.A., Seckler, M.M., Ingle, A.P., Gupta, I., Galdiero, S., Galdiero, M., Gade, A., Rai, M. 2014. Silver nanoparticles: Therapeutical uses, toxicity, and safety issues. J. Pharm. Sci. 103: 1931-1944.

Fayaz, A., Balaji, K., Girilal, M., Yadav, R., Kalaichelvan, P., Venketesan, R. 2010. Biogenic synthesis of silver nanoparticles and their synergistic effect with antibiotics: a study against gram-positive and gram-negative bacteria. Nanomedicine. 6: 103-109.

Franci, G., Falanga, A., Galdiero, S., Palomba, L., Rai, M., Morelli, G., Galdiero, M. 2015. Silver nanoparticles as potential antibacterial agents. Molecules. 20(5):8856-8874.

Gattuso, H., Besancenot, V., Grandemange, S., Marazzi, M., Monari, A. 2016. From noncovalent binding to irreversible DNA lesions: nile blue and nile red as photosensitizing agents. Sci. Rep. 6: 28480.

Howden, B, P., Grayson, M, L. 2006. Dumb and dumber - the potential waste of a useful antistaphylococcal agent: emerging fusidic acid resistance in Staphylococcus aureus. Clin Infect Dis. 42:394-400.

Jain, J., Arora, S., Rajwade. J.M., Omray, P., Khandelwal, S., Paknikar, K.M. 2009. Silver nanoparticles in therapeutics: Development of an antimicrobial gel formulation for topical use. Mol. Pharmaceutics.6: 1388-401.

Jori, G., Fabris, C., Soncin, M., Ferro, S., Coppellotti, O., Dei, D., Fantetti, L., Chiti, G., Roncucci, G. 2006. Photodynamic therapy in the treatment of microbial infections: basic principles and perspective applications. Lasers Surg Med. 38, 468-481.

Kashef, N., Esmaeeli-Djavid, G., Siroosy, M., Taghi-Khani, A., Hesami-Zokai, F., Fateh, M. 2011. Photodynamic inactivation of drug-resistant bacteria isolated from diabetic foot ulcers. Iran $\mathbf{J}$ Microbiol.3 (1): 36-41.

Kong, H., Jang, J. 2008. Antibacterial properties of novel poly (methyl methacrylate) nanofiber containing silver nanoparticles. Langmuir. 24:2051-2056.

Li, P., Li, J., Wu, C., Wu, Q. 2005.Synergistic antibacterial effects of $\beta$-lactam antibiotic combined with silver nanoparticles. Nanotechnol. 16: 1912-1917.

Lok, C., Ho, C., Chen, R., Che, C.M., 2006. Proteomic analysis of the method of antibacterial action of silver nanoparticles. J Proteome Res. 5: 916924.

Mishra M, Kumar H, Tripathi K. 2008. Diabetic delayed wound healing and the role of silver nanoparticles digest. $\mathbf{J}$ Nanomaterials and Biostructures. 3: 49.

Pal, S., Tak, Y., Song, J. 2007. Does the antibacterial activity of silver nanoparticles depend on the shape of the nanoparticle? A study of the Gramnegative bacterium Escherichia coli. Appl Environ Microbiol. 73: 1712-1720.

Petica, A., Gavriliu, S, Lungu, M., Buruntea, N., Panzaru, C. 2008.Colloidal silver solutions with antimicrobial properties. Mater Sci Eng. 152:22-27.

Rai, M, K., Deshmukh, S, D., Ingle, A,P., Gade, A,K. 2012. Silver nanoparticles: the powerful nanoweapon against multidrugresistant bacteria. J Appl Microbiol. 112(5):841-852.

Ruden, S., Hilpert, K., Berditsch, M., Wadhwani, P., Ulrich, A. 2009. 
Synergistic interaction between silver nanoparticles and membranepermeabilizing antimicrobial peptides. Antimicrob Agents Chemother. 53(8); 3538-3540.

Salomoni, R., Leo, P., Rodrigues, M,F,A. 2015. Antibacterial activity of silver nanoparticles (AgNPs) in Staphylococcus aureus and cytotoxicity effect in mammalian cells. Formatex Microbiol. 5:851-857.

Segun, G, J. 2004. Bacteria associated with cultures of Psathyrella atroumbonata and Schizophyllum commune. Afri J Biomed Res. 7(3): 139-43.

Seppala, H., Klaukka, T., Vuopio-Varkila, J., Muotiala, A., Helenius, H., Lager, K., Huovinen, P. 1997. The effect of changes in the consumption of macrolide antibiotics on erythromycin resistance in group A Streptococci in Finland. Finnish Study Group for Antimicrobial Resistance. N. Engl. J. Med. 337: 441446.

Shahverdi, A, R., Fakhimi, A., Shahverdi, H,R., Minaian, S. 2007. Synthesis and effect of silver nanoparticles on the antibacterial activity of different antibiotics against Staphylococcus aureus and Escherichia coli. Nanomedicine. 3(2): 168-171.

Shrivastava, S., Bera, T., Roy, A., Singh, G., Ramachandrarao, P., Dash, D. 2007. Characterisation of enhanced antibacterial effects of novel silver nanoparticles. Nanotechnology. 18: 1-9.

Sondi, I., Salopek-Sondi, B. 2004. Silver nanoparticles as antimicrobial agent: A case study on E. coli as a model for Gram-negative bacteria. J. Colloid Interface Sci. 275: 177-182.

Todar, K, 2005. Todar's online textbook of bacteriology. University of WisconsinMadison, Department of Bacteriology. Available from: http://textbookof bacteriology.net/V.vulnificus.html. [Accessed on 3 Nov, 2015].

Turkevich, J., Stevenson, P.C., Hillier, J. 1951.A study of the nucleation and growth processes in the synthesis of colloidal gold. Dis Faraday Soc. 11: 5575.

Usacheva, M., Teichert, M., Biel, M. 2001. Comparison of the methylene blue and toluidine blue photobactericidal efficacy against gram-positive and gram-negative microorganisms. Lasers Surg Med. 29:165-173.

Walker, B., Barrett, S., Polasky, S., Galaz, V., Folke, C., Engstrom, G., Ackerman, F., Arrow, K., Carpenter, S., Chopra, K.2009. Environment. Looming globalscale failures and missing institutions. Science. 325: 1345-1346.

Yoon, K., Hoon Byeon, J., Park, J, H., Hwang, J. 2007. Susceptibility constants of Escherichia coli and Bacillus subtilis to silver and copper nanoparticles. Sci Total Environ. 373 (2-3):572-575.

Zeina, B., Greenman, J., Purcell, W, M., Das, B. 2001. Killing of 17 cutaneous microbial species by photodynamic therapy. $\mathrm{Br} \mathrm{J}$ Dermatol. 144: 274-278.

\section{How to cite this article:}

Dalia El-Sayed Metwally, Eglal Abd El-Salam El-Sherbiny, Heba Saed Ramadan, Moustafa Moustafa Mohamed Ahmed and Mo'men Gameel Abd Elmageed. 2018. Study of the Antimicrobial Effect of the Different Combinations of Silver Nano-Particles, Antibiotics, Laser and Photo-Sensitizer on Gram Positive and Gram Negative Bacteria. Int.J.Curr.Microbiol.App.Sci. 7(04): 2947-2960. doi: https://doi.org/10.20546/ijcmas.2018.704.335 